\title{
Visualizing and Quantifying Deformation Microstructures in Cold Sprayed Materials
}

\author{
Luke N. Brewer ${ }^{1}$,Tian Liu ${ }^{1}$, Jeremy D. Leazer ${ }^{2}$, J.F. Schiel ${ }^{2}$, E.S.K. Menon ${ }^{2}$ \\ 1. Metallurgical and Materials Engineering, University of Alabama, Tuscaloosa, AL, USA. \\ 2. Mechanical and Aerospace Engineering, Naval Postgraduate School, Monterey, CA, USA.
}

This paper examines the deformation microstructures produced in metallic alloys by the cold gas dynamic spray ("cold spray") process. CS deposition is a solid-state deposition process in which high velocity $(300-1200 \mathrm{~m} / \mathrm{s})$, small $(10-50 \mu \mathrm{m})$ metallic particles impact and adhere to a substrate. As the spray gun is rastered over the substrate surface a coating, and even a three-dimensional solid, can be produced. The CS process is now being used for corrosion protection, mitigation, and repair. [1] This process produces metallic materials under extreme conditions. The combination of small particle size and high impact velocity produces strain rates on the order of $10^{6}-10^{9} / \mathrm{s}$ with average particle strains on the order of $50 \%$. Understanding the deformation mechanisms and the microstructures that they produce is key to controlling the cold spray process and the mechanical properties of the deposited material. This talk will describe the use of electron microscopy and diffraction techniques, e.g. SEM, TEM, electron backscatter diffraction (EBSD), transmission kikuchi diffraction (TKD), and precession electron diffraction (PED), to visualize and to quantify plastic deformation in aluminium alloy and austenitic stainless steel materials.

Cold spray deposition of $\mathrm{Al}-\mathrm{Cu}(2-5 \mathrm{wt} \% \mathrm{Cu})$ alloys and austenitic stainless steels (304 and 316) was accomplished with a Centerline P-series low-pressure cold spray system using helium as the spray gas. A range of gas pressures and temperatures was used to control the particle velocities during deposition. A Tecnar CSM eEVOLUTION particle velocimeter was used to measure the particle velocities during flight. After deposition, cross sections were prepared using metallography and focused ion beam (FIB) techniques to produce both SEM/EBSD samples and TKD, TEM, and PED samples.

Cold spray deformation microstructures are composite in nature with a coarser grained interior at the center of prior particles and with a finer grained region in between prior particles (Figure 1a). The low angle grain boundary density is notably higher in the prior particle centers (Figure 1b). The effect of plastic deformation on intragranular misorientation can be visualized using grain reference orientation deviation (GROD) maps (Figure 1c). [2] In these maps, it can be seen that the fine grained regions in between prior particles have recrystallized. The deformation microstructure is similar for $\mathrm{Al}-2 \mathrm{wt} \% \mathrm{Cu}$ and $\mathrm{Al}-5 \mathrm{wt} \% \mathrm{Cu}$, although the grain size is slightly smaller for the higher copper content material. Both cold sprayed coatings have a substantially smaller grain size than in the starting powder. This same deformation structure is also observed for the austenitic stainless steels, although the extent of it is a function of steel powder type. [3] The EBSD data for the Al-Cu coatings also showed, for the first time, a weak, but measurable, $<110>$ fiber texture along the deposition direction (Figure 2).

\section{References:}

[1] J. Villafuerte and D. Wright, Advanced Materials \& Processes 168 (2010) p. 53-55.

[2] S.I. Wright et al., Microscopy and Microanalysis 17 (2011), p. 316-329.

[3] L.N. Brewer et al., Surface Coatings and Technology 334 (2018) p. 50-60. 
[4] The authors acknowledge funding from Mr. William Nickerson of the Office of Naval Research, Grant N0001414WX00148, and the college of engineering at the University of Alabama.
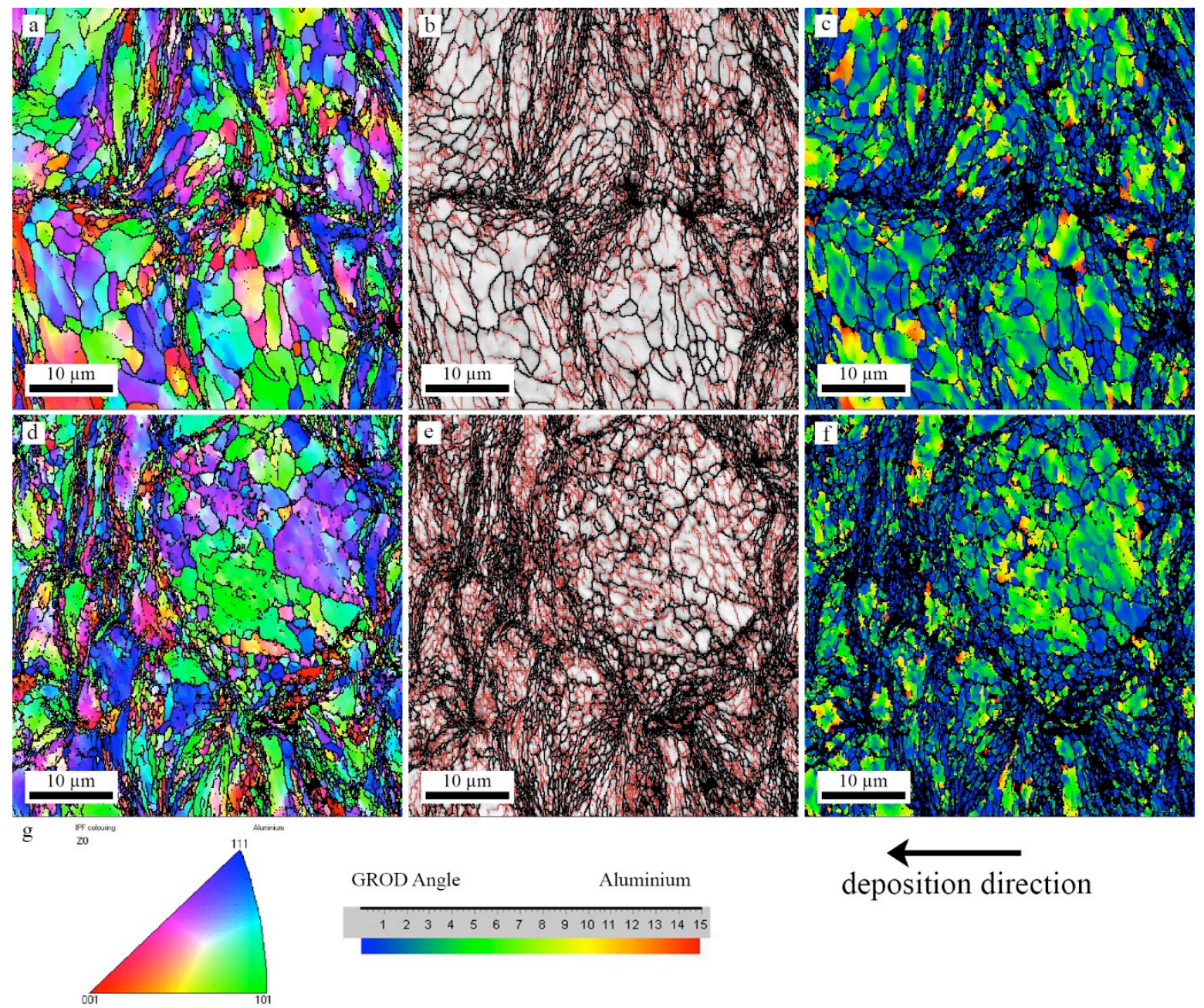

Figure 1. EBSD measurements of the Al-2Cu coating (a-c) and Al-5Cu coating (d- f) sprayed at $225^{\circ} \mathrm{C}$ and 1.21 MPa, (a, d) orientation map, (b, e) band contrast, (c, f) GROD angle map. High-angle grain boundaries $\left(>10^{\circ}\right)$ (HAGB) in black were overlaid in (a-f) and low-angle grain boundaries $\left(2^{\circ}-10^{\circ}\right)$ (LAGB) in red were overlaid in (b, e). (g) shows legends for the orientation and GROD angle maps.
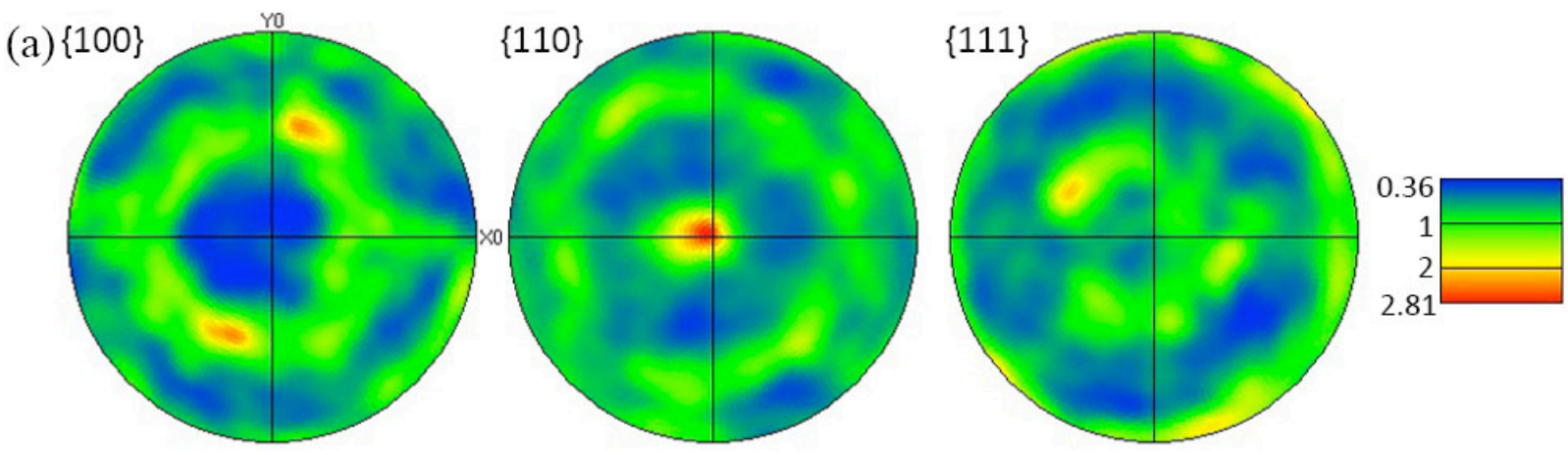

Figure 2. Pole figures of the $\mathrm{Al}-2 \mathrm{Cu}$ coatings sprayed at $275^{\circ} \mathrm{C}$ and $1.21 \mathrm{MPa}$. The $\mathrm{Z}$-axis (out of the page) is the deposition direction. 